\title{
ANALISIS KUALITAS LAYANAN E-COMMERCE MENGGUNAKAN TWITTER API (Studi Kasus: Tokopedia, Lazada dan Bukalapak)
}

\section{ANALYSIS OF E-COMMERCE SERVICE QUALITY USING TWITTER API \\ (Case Studi: Tokopedia, Lazada and Bukalapak)}

\author{
Anthoni Rivai Pulakiang ${ }^{1}$, I Made Nomo Wiranatha ${ }^{2}$, John Reimon Batmetan ${ }^{3}$ \\ ${ }^{1,2}$ Magister Teknik Informatika, Fakultas Teknik Industri, \\ Universitas Atma Jaya Yogyakarta \\ ${ }^{3}$ Fakultas Teknik, Universitas Negeri manado \\ anthonipulakiang@gmail.com
}

\begin{abstract}
Abstrak
Berkembangnya internet memberikan akses yang kuat pada penggunaan media social dan proses komunikasi bisnis dalam ruang digital. Penggunaan media social untuk melakukan proses transaksi bisnis semakin ramai digunakan dikalangan generasi milenial. Dalam beberapa e-commerce yang sedang berkembang di Indonesia, banyak evaluasi layanan yang diberikan oleh pelanggan lewat komentar di social media twitter. Dengan data yang diambil berdasarkan pencarian atas pendapat customer pada layanan e-commerce yang terhubung pada Twitter API ditemukan hasil yang berbeda dari 3 e-commerce yang diteliti. Hasil ini menunjukan bahwa e-commerce yang paling banyak mendapat komentar negative atau evaluasi dari pelanggan ada pada Lazada sedangkan pada tokopedia dan bukalapak hasil analisis menunjukan kesamaan presentase. Artinya tokopedia dan bukalapak mempunyai tingkat evaluasi dan komentar negative yang sama. Kedepannya diharapkan penggunaan $e$ commerce di Indonesia semakin baik dan terus memberikan layanan yang baik bagi kepuasan pelanggan.
\end{abstract}

Kata Kunci: Customer Relationship Menagement, e-commerce, twitter.

\begin{abstract}
The development of the internet provides strong access to the use of social media and business communication processes in the digital space. The use of social media to conduct the business transaction process increasingly crowded among millennial generations. In some of the growing e-commerce in Indonesia, many evaluation services provided by customers through comments on social media twitter. With data were taken based on the search for customer opinions on e-commerce services linked to the Twitter API found different results from the 3 e-commerce studied. These results indicate that e-commerce is the most widely received negative comments or evaluation of the customer is on Lazada, while in Tokopedia and Bukalapak analysis shows the similarity percentage. This means that Tokopedia and Bukalapak have the same level of evaluation and negative comments. In the future, it is expected that the use of e-commerce in Indonesia will be better and continue to provide good service for customer satisfaction.
\end{abstract}

Keywords: Customer Relationship Management, e-commerce, twitter. 


\section{PENDAHULUAN}

Sosial media merupakan sarana yang paling sering digunakan untuk memperlihatkan aktivitas pribadi dan social dari pengguna dalam dunia. maya. Dalam hal ini sangat mempengaruhi informasi yang digunakan dalam mengekspos kegiatan atau aktivitas yang bersifat pribadi. Sehingga mengakibatkan krisis privasi dari para pengguna social media (sosmed). Media sosial merupakan salah satu aktivitas online favorit yang digunakan oleh publik hampir setiap hari[1]. Laporan yang pernah dikeluarkan oleh Global Web Index pada tahun 2015 lalu mengenai trend terbaru berkenaan dengan jejaring sosial menemukan bahwa setiap empat menit yang dihabiskan seseorang di internet digunakan untuk mengakses jejaring sosial, seiring dengan peningkatan penggunaan internet pada smartphone[2]. Penggunaan Twitter, berdasarkan data PT. Bakrie Telecom, memiliki 19,5 juta pengguna di Indonesia dari total 500 juta pengguna global. Laporan tersebut juga menemukan bahwa kebanyakan masyarakat saat ini memiliki kurang lebih lima akun media social, di mana laporan lainnya menyatakan bahwa jejaring sosial merupakan aktivitas yang paling banyak menghabiskan waktu pengguna internet di masa sekarang ini[3],[4].

Dalam penggunaannya media sosial sendiri tidak lagi hanya digunakan untuk semata-mata berjejaring didunia maya tetapi pada dewasa ini media sosial juga sering digunakan oleh generasi $\mathrm{z}$ untuk proses penjualan, pemasaran produk, pelayanan konsumen serta untuk proses bisnis online yang sering dikenal dengan online shop atau belanja online[5]. Meskipun secara khusus sudah ada aplikasi yang dibuat untuk melakukan proses belanja online tersebut seperti Tokopedia, Lazada, Bukalapak dan lain-lain, penggunaan social media sangat berpengaruh juga dalam proses penjualan online karena seperti yang diuraikan diatas bahwa sebagian besar masyarakat generasi sekarang pasti mempunyai akun dimedia social seperti Facebook, twitter dan Instagram, sehingga lebih mempermudah proses transaksi penjualan online[6]-[10]. Penggunaan smartphone yang semakin massiv memungkinkan pengguna untuk melakukan aktivitas secara mobile atau portable. Misalnya; pembayaran, penyetoran, pemesanan, dan hal apapun yang mengenai proses bisnis bisa dilakukan menjadi lebih mudah dan efektif dari segi waktu[8], [10]-[12]. Toko online merupakan sarana yang dapat mempermudah untuk melakukan proses jual beli. Namun toko online juga memiliki banyak kelemahan seperti sering terjadi kasus penipuan, barang yang dikirim tidak sesuai dengan pesanan dan lain sebagainya[13], [14]. Tujuannya untuk meningkatkan layanan mobile bisnis online shop lewat social media berdasarkan evaluasi, kritik, saran, kelebihan serta kekurangan dari online shop[15]-[17].

\section{Rumusan Masalah}

Berdasarkan uraian pada latar belakang masalah sebelumnya, maka dapat dirumuskan pokok permasalahan penelitian adalah: Bagaimana menganalisis dan merekomendasi Aplikasi e-Commerce yang baik bagi konsumen dengan memanfaatkan media jejaring sosial twitter.

\section{LANDASAN TEORI \\ E-Commerce}

Perdagangan elektronik (electronic commerce, disingkat EC, atau e-commerce) mencangkup proses pembelian, penjualan, transfer, atau pertukaran produk, layanan 
atau informasi melalui jaringan komputer, termasuk internet[18]

\section{Twitter API}

API Twitter atau Application Programming Interface (API) twitter adalah suatu program atau aplikasi yang disediakan oleh twitter untuk mempermudah developer lain dalam mengakses informasi yang ada di website twitter. Pendaftaran sebagai developer aplikasi twitter untuk menggunakan API twitter dapat dilakukan di lama https://dev.twitter.com. Setelah mendaftar developer akan mendapatkan consumer key, consumer access, access token dan access token secret yang akan digunakan sebagai syarat otentifikasi dari aplikasi yang akan kita bangun. Tujuan dari otentifikasi adalah untuk hak akses developer dalam mengunduh data yang ada di twitter.[19]

\section{METODE PENELITIAN}

Penelitian ini dilakukan dengan langkahlangkah berikut:

\section{1) PengumpulanData}

Data yang digunakan dalam penelitian ini adalah data tweet dari twitter tentang kualitas layanan e-commerce yang dirasakan oleh customer.

\section{2) Preprocessing}

Preprocessing data tweet dilakukan bertujuan untuk menyeragamkan bentuk kata, menghilangkan noise dan mengurangi volume kata saat melakukan alanisis data sentimen. Prosesnya dapat dilihat pada gambar dibawah ini.

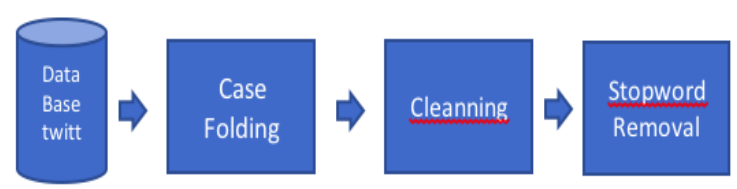

Gambar 1. Proses Preprocessing data tweet

\section{3) AnalisaData}

Pada tahap ini dilakukan proses untuk menganalisa dan mengolah hasil dari data yang telah dikumpulkan. Hasil analisis dari data yang ada diharapkan dapat mengetahui layanan e-commerce mana yang paling sering dikeluhkan olehcustomer.

\section{HASIL PEMBAHASAN \\ Proses pengumpulan data}

Proses pengambilan data dilakukan melalui pencarian pendapat customer pada layanan e-commerce yang terhubung pada Twitter API. Hasil pencarian tersebut berupa data kotor atau tweet kotor yang belum di olah dan dianalisis. Setelah itu dilakukan prerpocessing data untuk membersihkan data. Data Tweet di peroleh dari Search API yang di sediakan oleh twitter, kemudian data dari API tersebut di disimpan pada database. Pada saat pengumpulan data penelitian ini, peneliti memasukan 3 keyword berupa LazadaID, tokopediacare dan bukalapak untuk mendapat tweet dari customer tentang opini pada objek penelitian e-commerce tersebut. Tampilan tweet positif dan negative dapat dilihat pada gambar 1 dan 2 .

\section{Contoh Tampilan tweet (negative \& positive)}

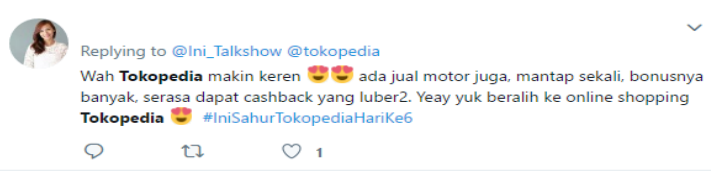

Gambar 1. Tampilan tweet positif

trx 180856234445 di website JNE sudah delivered,tapi di web bukalapak masih on proces,mohon segera di update

Q 1 〔】 0

Gambar 2. Tampilan tweet negatif 


\section{Preprocessing}

Tahap preprocessing adalah tahap dimana data di download dari social media twitter, lalu proses case folding, proses cleaning, dan proses stop removal.

\section{Case Folding Process}

Tahap case folding process adalah tahap memperbaiki komentar atau tweet dari yang awlnya mempunya huruf capital menjadi lowercase (huruf kecil) semuanya. Langkah-langkah case folding process dapat dilihat pada salah satu contoh tweets berikut: "apa memang selama ini @TokopediaCare?" dirubah menjadi “apa memang selama ini @tokopediacare?”. Prosesnya dapat dilihat pada table 1 .

\section{Tabel 1. Proses case folding}

\begin{tabular}{|l|l|}
\hline $\begin{array}{l}\text { Teks } \\
\text { sebelum } \\
\text { dilakukan } \\
\text { proses Case } \\
\text { Folding }\end{array}$ & $\begin{array}{l}\text { Lihat barang promo menarik di } \\
\text { @tokopedia, masuk ke cart, check } \\
\text { out deh, transfer via virtual } \\
\text { account. Sudah lebih dari 7 jam } \\
\text { belum terverifikasi, apa memang } \\
\text { selama ini @ TokopediaCare? } \\
\text { Mohon follow up nya, thx a lot }\end{array}$ \\
\hline $\begin{array}{l}\text { Teks } \\
\text { sesudah } \\
\text { dilakukan } \\
\text { proses Case } \\
\text { Folding }\end{array}$ & $\begin{array}{l}\text { lihat barang promo menarik di } \\
\text { @ tokopedia, masuk ke cart, check } \\
\text { sudah lebih dari 7 jam belum } \\
\text { terverifikasi, apa memang selama ini } \\
\text { @ tokopediacare? mohon follow up }\end{array}$ \\
\hline
\end{tabular}

\section{Cleaning data process}

Dari data yang diambil di social media twitter ada beberapa komponen yang biasa ada di tweet atau komentar seseorang yakni, komponen username, komponen URL (Uniform Resource Locator), dan dan komponen "RT" (tanda retweet). Dari tiga komponen yang ada yaitu username, URL, dan "RT" tidak memiliki pengaruh terhadap nilai sentimen, oleh karena itu ketiga komponen itu akan dibuang dan tidak digunakan lagi. Komponen seperti username dapat diidentifikasikan dengan munculnya karakter ‘@'. Selain pada komponen username, karakter ini ('@') sering juga digunakan untuk memanggil dan men-tag suatu tempat dan nama seperti @ tokopedia. Tetapi nama tempat juga tidak memberikan pengaruh yang signifikan pada saat menganalisis sentimen lewat tweer pelanggan, sehingga nama tempat tersebut juga harus dihapus. yang dapat dilihat pada table 2. Langkah-langkah pada tahap cleaning data dapat dilihat pada table 2 .

Tabel 2. Cleaning data process

\begin{tabular}{|l|l|}
\hline $\begin{array}{l}\text { Teks } \\
\text { sebelum } \\
\text { dilakukan } \\
\text { proses } \\
\text { Cleanning }\end{array}$ & $\begin{array}{l}\text { More } \\
\text { lihat barang promo menarik di } \\
\text { @ tokopedia, masuk ke cart, check } \\
\text { out deh, transfer via virtual } \\
\text { account. sudah lebih dari 7 jam } \\
\text { belum terverifikasi, apa memang } \\
\text { selama ini @ } \text { tokopediacare? } \\
\text { mohon follow up nya, thx a lot }\end{array}$ \\
\hline $\begin{array}{l}\text { Teks } \\
\text { sesudah } \\
\text { dilakukan } \\
\text { proses } \\
\text { Cleanning }\end{array}$ & $\begin{array}{l}\text { lihat barang promo menarik di, } \\
\text { masuk ke cart, check out deh, } \\
\text { transfer via virtual account. sudah } \\
\text { lebih dari 7 jam belum terverifikasi, } \\
\text { apa memang selama ini? mohon } \\
\text { follow up nya, thx a lot }\end{array}$ \\
\hline
\end{tabular}

\section{Stopword Removal}

Tahap Stopword Removal adalah proses pembuangan kata yang tidak memiliki arti atau tidak relevan. Contohnya kumpulan tweets yang telah melewati tahap cleaning dihilangkan karakter, tanda baca, serta katakata umum yang tidak memiliki makna atau informasi yang dibutuhkan dalam menganalisis sentimen. Prosesnya dapat dilihat pada table 3 .

\section{Tabel 3. Proses stopword removal}

\begin{tabular}{|l|l|}
\hline $\begin{array}{l}\text { Teks sebelum } \\
\text { dilakukan } \\
\text { proses }\end{array}$ & $\begin{array}{l}\text { More } \\
\text { lihat barang promo menarik di, } \\
\text { stopword } \\
\text { removal }\end{array}$ \\
& $\begin{array}{l}\text { transfer via virtual account. } \\
\text { sudah lebih dari } 7 \text { jam belum } \\
\text { terverifikasi, apa memang }\end{array}$ \\
\hline
\end{tabular}




\begin{tabular}{|l|l|}
\hline & $\begin{array}{l}\text { selama ini? mohon follow up } \\
\text { nya, thx a lot }\end{array}$ \\
\hline $\begin{array}{l}\text { Teks sesudah } \\
\text { dilakukan } \\
\text { proses } \\
\text { stopword } \\
\text { removal }\end{array}$ & $\begin{array}{l}\text { lihat barang promo menarik di } \\
\text { masuk ke cart check out deh } \\
\text { transfer via virtual account sudah } \\
\text { lebih dari 7 jam belum } \\
\text { terverifikasi apa memang selama } \\
\text { ini mohon follow up nya thx a lot }\end{array}$ \\
\hline
\end{tabular}

\section{Analisa}

Pada tahap ini dilakukan proses untuk menganalisa dan mengolah hasil dari data yang telah dikumpulkan. Dari data yang ada dibagi menjadi 2 opini atau pendapat yaitu pendapat positif dan pendapat negatif. Setelah itu di bandingkan dari $3 \mathrm{~m}$ commerce yang ada untuk menentukan tingkat opini yang paling banyak dalam bentuk presentase. Langkah berikutnya dilakukan proses mencari layanan yang paling banyak dikeluhkan oleh customer dan diurutkan dari yang paling rendah sampai paling tinggi, kemudian dibuat dalam bentuk diagram presentase. Tahap ini juga kita dapat mengetahui mana $e$ commerce yang memiliki tingkat keluhan yang paling banyak dan sedikit. Sehingga dengan yang hasil yang diperoleh dapat menjadi tolak ukur untuk e-commerce yang lain dalam meningkatkan kualitas layanan mereka dan dapat memberikan informasi yang baik bagi pengguna dalam melakukan proses pembelian pada setiap e-commerce yang ada di Indonesia. Dalam melakukan transaksi juga perlu melihat dan memilih $e$ commerce dengan baik agar terhindar dari berbagai ancaman dunia internet.

\section{Proses Presentase}

Dari data yang ada diolah dan dianalisis ditemukan bahwa sebagian besar pengguna melakukan keluhan layanan dari setiap $e$ commerce dibandingkan dengan komentar atau tweet positif. Hasilnya dapa dilihat pada gambar berikut.

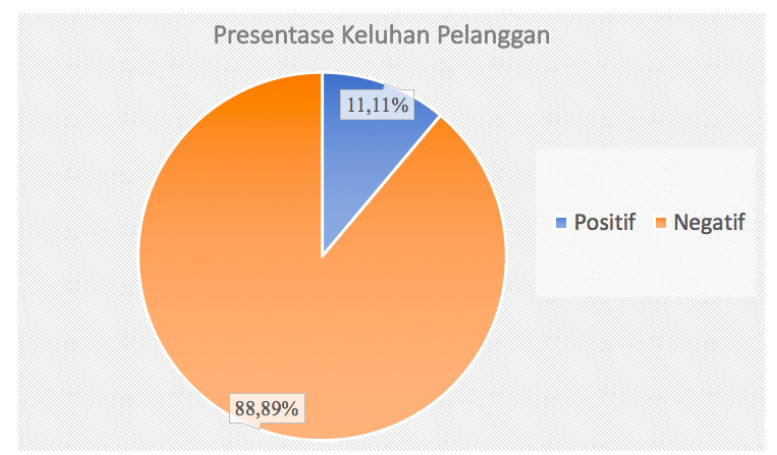

Gambar 3. Presentase keluhan pelanggan.

Tingkat presentase keluhan layanan (admin, respon admin, bagian pemesanan, proses refound, bagian pengiriman, bagian tracking, bagian kurir). Hasil analisis keluhan pelanggan pada e-commerce dapat dilihat pada tabel 4 .

Tabel 4. Presentase keluhan pelanggan pada 3 layanan e-commerce.

\begin{tabular}{|c|c|c|c|c|c|}
\hline \multirow[t]{2}{*}{ No } & \multirow{2}{*}{$\begin{array}{l}\text { Keluha } \\
\text { n } \\
\text { Layana } \\
\text { n }\end{array}$} & \multicolumn{4}{|c|}{ Presentase } \\
\hline & & $\begin{array}{l}\text { Laza } \\
\text { da }\end{array}$ & $\begin{array}{l}\text { Bukala } \\
\text { pak }\end{array}$ & $\begin{array}{l}\text { Tokope } \\
\text { dia }\end{array}$ & $\begin{array}{l}\text { Gabun } \\
\text { gan } \\
\text { E- } \\
\text { Comme } \\
\text { rce }\end{array}$ \\
\hline 1 & $\begin{array}{l}\text { Update } \\
\text { status } \\
\text { pesanan } \\
\text { lama }\end{array}$ & $\begin{array}{l}17,86 \\
\%\end{array}$ & $11,54 \%$ & $26,92 \%$ & $18,75 \%$ \\
\hline 2 & $\begin{array}{l}\text { Trackin } \\
\mathrm{g} \\
\text { bermasa } \\
\text { lah }\end{array}$ & $\begin{array}{l}3,57 \\
\%\end{array}$ & $19,23 \%$ & $7,69 \%$ & $10 \%$ \\
\hline 3 & $\begin{array}{l}\text { System } \\
\text { pembay } \\
\text { aran } \\
\text { atau } \\
\text { top-up } \\
\text { bermasa } \\
\text { lah }\end{array}$ & $\begin{array}{l}7,14 \\
\%\end{array}$ & $11,54 \%$ & $34,61 \%$ & $17,5 \%$ \\
\hline 4 & $\begin{array}{l}\text { Quality } \\
\text { control } \\
\text { pelapak } \\
\text { buruk }\end{array}$ & $\begin{array}{l}7,14 \\
\%\end{array}$ & $7,69 \%$ & - & $5 \%$ \\
\hline 5 & $\begin{array}{l}\text { Produk } \\
\text { cacat }\end{array}$ & $\begin{array}{l}17,86 \\
\%\end{array}$ & - & $3,85 \%$ & $7,5 \%$ \\
\hline
\end{tabular}




\begin{tabular}{|c|c|c|c|c|c|}
\hline & $\begin{array}{l}\text { atau } \\
\text { palsu }\end{array}$ & & & & \\
\hline 6 & $\begin{array}{l}\text { Refound } \\
\text { atau } \\
\text { return } \\
\text { bermasa } \\
\text { lah }\end{array}$ & $\begin{array}{l}17,86 \\
\%\end{array}$ & $7,69 \%$ & $3,85 \%$ & $10 \%$ \\
\hline 7 & $\begin{array}{l}\text { Penipua } \\
\mathrm{n}\end{array}$ & $\begin{array}{l}3,57 \\
\%\end{array}$ & $3,85 \%$ & $3,85 \%$ & $3,75 \%$ \\
\hline 8 & $\begin{array}{l}\text { Pengiri } \\
\text { man } \\
\text { barang } \\
\text { bermasa } \\
\text { lah }\end{array}$ & $\begin{array}{l}17,86 \\
\%\end{array}$ & $11,54 \%$ & $3,85 \%$ & $11,25 \%$ \\
\hline 9 & $\begin{array}{l}\text { System } \\
\text { atau } \\
\text { server } \\
\text { error }\end{array}$ & - & $15,38 \%$ & $7,69 \%$ & $7,5 \%$ \\
\hline 10 & $\begin{array}{l}\text { CS slow } \\
\text { respond }\end{array}$ & $\begin{array}{l}7,14 \\
\%\end{array}$ & $11,54 \%$ & - & $6,25 \%$ \\
\hline 11 & $\begin{array}{l}\text { Fitur } \\
\text { shake } \\
\text { mengga } \\
\text { nggu }\end{array}$ & - & - & $7,69 \%$ & $2,5 \%$ \\
\hline
\end{tabular}

Dari tabel diatas dapat dilihat bahwa ada perbedaan presentase jumlah keluhan dari tiga e-commerce yang di teliti. Perbedaan ini menunjukan bahwa setiap konsumen memiliki tingkat keluhan sesuai dengan kualitas layanan. Pada e-commerce Lazada terdapat 4 tingkat keluhan yang paling tinggi yaitu pada poin Update status pesanan lama, Produk cacat atau palsu, Refound atau return bermasalah, dan Pengiriman barang bermasalah dengan nilai 17,86\%. Pada e-commerce bukalapak 2 poin yang menempati posisi paling tinggi yaitu "Trackring bermasalah dan system atau server error" dengan nilai presentase $19,23 \%$ dan $15,38 \%$. Dan pada e-commerce tokopedia tingkat keluhan yang paling tinggi terdapat pada "system pembayaran atau proses top-up bermasalah dan update status pesanan lama" dengan presentase $34,61 \%$ dan $26,92 \%$. Jika ketiganya digabung tingkat keluhan yang paling tinggi berada pada system pembayaran atau proses top-up bermasalah dan update status pesanan lama" dengan presentase $18,75 \%$ dan $17,5 \%$.

\section{KESIMPULAN}

Kesimpulannya adalah kita dapat melihat dan menilai dari 3 e-commerce yang sedang berkembang di Indonesia, mana e-commerce yang memiliki tingkat layanan yang baik dan mana e-commerce yang layanannya banyak dikeluhkan oleh pelanggan. Dalam hal ini Lazada merupakan $e$-commerce yang paling banyak dikeluhkan layanannya. Untuk itu kedepannya diharapkan penelitian ini dapat membantu perusahan e-commerce untuk mengevaluasi diri dan system yang sedang dijalankan dan memperbaiki proses bisnis yang menjadi evaluasi dari pelanggan agar menjadi lebih baik.

\section{DAFTAR PUSTAKA}

[1]R. A. Setiawan and D. B. Setyohadi, "Understanding customers ' intention to use social network sites as complaint channel: an analysis of young customers 'perspectives," 2nd Int. Conf. Energy, Environ. Inf. Syst. (ICENIS 2017), vol. 31, p. 11014, 2018.

[2]R. Juwita, "Media Sosial dan Perkembangan Komunikasi Korporat," J. Penelit. Komun., vol. 20, no. 1, pp. 47-60, 2017.

[3]O. T. Prayitno, O. Cizela, A. A. Damiani, and D. B. Setyohadi, "Regulatory Framework Creation Analysis to Reduce Security Risks The Use of Social Media in Companies," Int. Conf. Inf. Tech., Comput. Electr. Eng., pp. 235-238, 2017.

[4]I. A. Syaiful, A. Verdaningrum, and K. Sari, "Faktor-faktor yang Memengaruhi Perilaku Konsumen 
dalam Bertransaksi di Media Sosial," vol. 1, no. 1, pp. 95-112, 2016.

[5]B. A. W. Wirawan, Suyoto, and A. D. Budiyanto, "Perancangan Model Konseptual Penggunaan Dan Penerimaan Media Sosial Untuk MBisnis," J. Sist. Dan Inform., vol. 11, no. 1, pp. 28-34, 2016.

[6]G. Aprinta, "Fungsi Media Online sebagai Media Literasi Budaya bagi Generasi Muda," The Messenger, vol. 5, no. 1, pp. 16-30, 2013.

[7]S. Priambada, "Manfaat Penggunaan Media Sosial Pada Usaha Kecil Menegah (UKM)," Sesindo, no. November, pp. 2-3, 2015.

[8]D. S. Pamungkas, N. A. Setiyanto, and E. Dolphina, "Analisis Sentiment Pada Sosial Media Twitter Menggunakan Naive Bayes Classifier Terhadap Kata Kunci 'Kurikulum 2013', J. Teknol. Inf., vol. 14, no. 4, pp. 299-314, 2015.

[9]N. D. Mentari, M. A. Fauzi, and L. Muflikhah, "Analisis Sentimen Kurikulum 2013 Pada Sosial Media Twitter Menggunakan Metode $K$ Nearest Neighbor dan Fe ....," vol. 2, no. August, pp. 2739-2743, 2018.

[10]N. B. Classifier, "Analisis Sentiment Pada Sosial Media Twitter Menggunakan Naive Bayes Classifier Terhadap Kata," vol. 14, no. 4, pp. 299-314, 2013.

[11]B. Supradono and A. N. Hanum, "Peran Sosial Media untuk Manajemen Hubungan dengan Pelanggan pada Layanan ECommerce," Vallue Added, vol. 7, no. 2, pp. 33-45, 2011.

[12]P. M. F. Coelho, P. P. Correia, and I. G. Medina, "Social Media: A New Way of Public and Political Communication in Digital Media,"
Int. J. Interact. Mob. Technol., vol. 11, no. 6, p. 150, 2017.

[13]S. Kasus, D. I. Bank, B. P. D. Diy, P. T. Prasetyaningrum, and I. Wisnubhadra, "SOCIAL CUSTOMER RELATIONSHIP MANAGEMENT SEBAGAI STRATEGI BISNIS PADA BANK," TELEMATIKA, vol. 13, no. 01, pp. 52-58, 2016.

[14]P. Lukas, T. Fandy, and Suyoto, " $M$ Commerce In Indonesia: Problems \& Prospects," Ijcait, vol. I, no. Ii, pp. 71-76, 2012.

[15]S. T. Heru and R. Siti, "Pengklasifikasian topik dan analisis sentimen dalam media sosial," Snasti, 2013.

[16]N. M. S. Hadna, P. I. Santosa, and W. W. Winarno, "Studi Literatur Tentang Perbandingan Metode untuk Proses Analisis Sentimen di Twitter," Semin. Nas. Teknol. Inf. dan Komun., vol. 2016, no. Sentika, pp. 57-64, 2016.

[17]I. F. Rozi, S. H. Pramono, and E. A. Dahlan, "Implementasi Opinion Mining ( Analisis Sentimen) untuk Ekstraksi Data Opini Publik pada Perguruan Tinggi," Electr. Power, Electron. Commun. Control. Informatics Semin., vol. 6, no. 1, pp. 37-43, 2012.

[18]Turban, David K, J. Lee, T. Liang, D. Turban. 2012. Electronic Commerce 7th Edition. United States: Pearson.

[19]Jaka Eka Sembodo, Erwin Budi Setiawan, ZK Abdurahman Baizal, Data Crawling Otomatis Pada Twitter, Indonesia Symposium on Computing (IndoSC) 2016, 24-25 September, 2016. PP 11-16, ISSN 2460-3295,2016 